\title{
Effect of Inclusion Versus Segregation on Reading Comprehension of EFL Learners with Dyslexia: Case of Lebanon
}

\author{
Ghada M. Awada ${ }^{1} \&$ Mar Gutiérrez-Colón ${ }^{2}$ \\ ${ }^{1}$, American University of Beirut, Beirut, Lebanon \\ ${ }^{2}$ Rovira i Virgili - Tarragona, Spain \\ Correspondence: Ghada M. Awada, American University of Beirut, Beirut, Lebanon. Tel: 961-7060-5396. \\ E-mail: ghadawada@gmail.com
}

\author{
Received: June 27, 2017 Accepted: August 2, 2017 Online Published: August 4, 2017 \\ doi: 10.5539/elt.v10n9p49 URL: http://doi.org/10.5539/elt.v10n9p49
}

\begin{abstract}
This study reports the relative effectiveness of the inclusion theory when the combined strategy instruction on improving the reading comprehension of narrative and expository texts for students with dyslexia is implemented. A total sample of 298 students of English as a foreign language from both public and private schools participated in the study which employed a pre-test- post-test control group design to investigate the efficacy of combined strategy instruction consisting of Graphic organizers, Visual displays, Mnemonic illustrations, Computer exercises, Prediction, Inference, Text structure awareness, Main idea identification, Summarization, and Questioning. The study concluded that combined strategy instruction in the field of the inclusion theory is more effective than regular instruction in improving reading comprehension when using narrative texts, but there's no difference, when using expository texts. There was no significant difference neither by gender nor by school types in all the grade levels under study.
\end{abstract}

Keywords: combined strategy instruction, dyslexia, inclusion theory, reading comprehension

\section{Introduction}

The present study is significant since it proposes a combined reading intervention treatment to improve the reading comprehension of learners with dyslexia in inclusive environments whereby social justice and equality are ensured, and learners without dyslexia are directed to improve their reading comprehension skills as well. Suggate (2016) indicated that there is scarcity in the research that investigates the long-term effect sizes of reading interventions in general and of intervention type in particular. However, some studies reported the long-term effects of one and not more than one intervention type such as phonemic awareness on improving reading comprehension (Swanson et al., 1999). As such, the low number of conducted studies does not provide a dependable estimation. Instruction is significantly effective when it is tailored in accordance with the needs of students who receive the instruction; however, there is no single strategy to ensure success for children of the same school-age. Some research provided insignificant differences indicating that there has been a focus on providing more individualized instruction than group interventions; in disagreement with general education learners who often receive instruction in big classroom-sized groups, interventions with learners with reading difficulties often take place in individualized environments (Goodwin \& Ahn, 2013).

Dyslexia causes a significant impairment in the development of reading correctness, reading fluency, reading comprehension, and spelling skills of all learners, in all grade levels. Dyslexia isn't coined with low IQ, visual perception problems, neurological impairment, or weak educational prospects (Heikkila \& Knight, 2012). The International Dyslexia Association showed that there is a remarkable increase in the number of learners with dyslexia; research indicates that 15 to 20 percent of the world's population has dyslexia (Heikkila \& Knight, 2012).

Mastropieri and Scruggs (1997) demonstrated that the intervention strategies, cognitive and direct instruction, when combined, showed remarkable gains in reading comprehension, and Swanson's (1999) findings conducted on a research of the effectiveness of the combined treatment showed that gains in reading comprehension are the direct result of the instructional components. However, Ellis, McDougall, and Monk (1996) and Treiman and Hirsh-Pasek(1985) indicated that young learners with dyslexia could have similar reading performance of those 
of the same age without dyslexia and even the learners with dyslexia could be faster at some visual processing tasks. As such, the researchers of the present study intended to examine as well whether the learners with dyslexia and their counterparts who are without dyslexia could show a similar level of reading achievement given they receive the same combined strategy treatment.

\subsection{Inclusive Environments Versus Segregation}

Shevlin, Winter and Flynn (2013) asserted that there has been a significant policy change in the special education systems in the Republic of Ireland towards the adoption of inclusion. The teacher's role in creating inclusive learning environments is essential, for the inclusive environments tremendously depend on having the teacher's knowledge, dispositions, cooperation, potentials, and attitudes. Research showed that teachers' perceptions of inclusion and awareness of the obstacles in establishing the inclusive learning environments are critical. A study conducted in some schools from urban and rural backgrounds and the participants were principals, teachers and support staff showed that teachers are aware of the importance of responding wisely to diversity within schools and they mostly support the principle of inclusion. However, the teacher's readiness and capacity along with the capacity of the schools to establish and develop inclusive environments remain a main concern. Social justice and equality were the significant factors in safeguarding inclusive environments. Research indicated that the combination of positive teacher principles and fears of apparent inadequacies hinder the development of inclusive learning practices and environments. The policy of creating inclusive learning environments asserts that all fundamental principles should ensure all young learners having education in their local schools irrespective of the special educational need they suffer from (Florian, Young, \& Rouse 2010). Moreover, creating inclusive environments requires having awareness of social diversity and increased recognition of the significance of inclusive environments that demand protection against the marginalization of children and young learners (Florian, Young, \& Rouse 2010).

Dyslexia is the most widely recognized form of reading disorder. Several studies have widely investigated the effects of dyslexia on children's reading comprehension. It was found that children with dyslexia often fail to easily recognize printed words, and they face difficulties that are different from those experienced as poor readers who can read accurately and fluently at a level suitable for their age but cannot comprehend what they read (Hulme \& Snowling, 2011). As such, although reading impairment has been studied several times, such condition is often unnoticed in classrooms as children may read fluently without showing any problem; the problems occur only when children are asked to answer questions related to the passage. The reading impairment some children experience is a hidden difficulty, and the children along with their teachers do not usually notice the reading problem.

\subsection{Purpose of the Study}

The aim of this study is twofold: 1) to explore the efficiency of integrating the learners with dyslexia with the learners without dyslexia; 2) to study the use of combining strategies to enhance reading comprehension in mixed groups (learners with dyslexia and learners without dyslexia).

\section{Literature Review}

\subsection{Theoretical Framework}

This study is framed within two global theoretical frameworks; construction-integration (C-I) model (Kintsch, 1988) and the reader's situation model (Van Dijk \& Kintsch, 1983). The modern reading theory involved the construction-integration (C-I) model (Kintsch, 1988) which entailed the reader's cognitive architecture and cognitive procedures related to retrieval operations and to text devices comprising argumentation connection that facilitated comprehension. The reader's situation model (Van Dijk \& Kintsch, 1983), the construction-integration (C-I) model and the reader's situation model entail inferential comprehension that pertain to the cognitive subtleties of text comprehension. The construction-integration (C-I) theory assumes that the text comprehension could be explicated by a collaborative combination of top-down process which is knowledge-guided and bottom-up process which is word-guided. Comprehension is a complex process that provides a set of interrelated assumptions which can form theoretical models with propositions.

Specifically, the present study is framed within the context of the inclusion and integration theories in opposition to the segregation theory; that is, should learners with dyslexia be grouped together and separated from learners without dyslexia, or should they be placed in a more inclusive setting where they are integrated with learners with dyslexia? Inclusion requires full engagement in general education; inclusion necessitates providing support and services to students with special needs within normalized settings and "without the isolation and stigma often associated with special education services" (Sapon-Shevin, 1996, p. 39). Integration differs from full 
inclusion where students with special needs are unquestionably placed in a regular classroom with learners without dyslexia for the whole day and have special instruction delivered in the regular class (Bunch, Finnegan, Humphries, Doré, \& Doré, 2005). Strategy Interventions theory is also a frame to the present study as interventions support and enable children to improve the reading comprehension skills (Logemann, 2000). This evidence-based research also indicates that many learners with dyslexia can and, in fact, do achieve reading comprehension and realize academic achievement results that are comparable to their peers when the appropriate intervention response is utilized (Deacon, Parrila, \& Kirby, 2006).

\subsection{Inclusion Theory}

In Lebanon, the imbalanced amount of work and the segregation imposed in some schools are amongst the manifestations of discrimination against the learners with dyslexia. In addition, some students who become labeled 'disabled' get to be stigmatized and consequently excluded from the workforce since they are not perceived as competent (Reid \& Valle, 2004). According to Riddick (2002), dyslexia is a 'hidden' disability, since sometimes it is not easily diagnosed. For this reason, people with dyslexia have been exposed to prejudice and discrimination and their academic failure was attributed to poor intellect (Macdonald, 2009, p. 354). Such students usually demonstrate high cognitive skills, for they may be bestowed in other areas such as mathematics, science, and arts.

Therefore, the education of students with disabilities in general and learners with dyslexia has been and continues to be a focus of educational reform in Lebanon. As such, some researchers assert that learners with dyslexia should be identified and placed in a segregated setting, where they receive a completely tailored education according to their special needs. However, other educationalists assert that the learning-disabled students should move to be integrated with the regular students. Integration can be defined as the placement of learners with disabilities in regular classes on a full-time or part-time basis with typically developing peers. In this model, the special education support examinations and help can be given inside the regular classroom, but more typically involve sending the student out of the regular class during some part of the school day to receive special instruction (Bunch, Finnegan, Humphries, Doré, \& Doré, 2005). Kemp, Segal and Cutter (2009) posit that children with a learning disability need support and that their own learning disability, or learning disorder, is not a problem related to intelligence. Integration can be seen as a constructive step in the acceptance of students with special needs into the regular classrooms of their local schools.

\subsection{Reading Versus Reading Comprehension}

Comprehension has been considered as the essence of reading (Honig et al., 2008). Comprehension remains difficult for learners with dyslexia and reading impairments although educators agree that comprehending written material may be the main objective of reading (Edmonds et al., 2009). Strategy instruction in comprehension is essential for enabling students to understand the purpose of reading and for providing them with the real-world skills that are required for comprehending text (Honig et al., 2008).

The significance of constructing meaning from text has made researchers infer that the most important outcome of reading is comprehension. Ness (2011) indicated that comprehension entails recalling information from text, eliciting themes, involving in higher order thinking skills, building a mental image of text, and comprehending text structure. Pressley (2008) also asserted that comprehension is the last outcome of proficient reading ability. The RAND Group defined reading comprehension as the method of extracting and building meaning through engagement and immersion with the passage.The teachers' dependence on single strategies may mainly be the result of the instructional materials that motivate teachers to rely on a select number of experimented single comprehension strategies, such as predicting, questioning, and prior knowledge (Ness, 2011).

\subsection{Reading Comprehension Theories}

Perfetti \& Stafura (2014) indicated that there is no single theory of reading since reading involves several components that cannot be encompassed in a single theory. Reading theories vary to involve word reading theories, learning to read theories, dyslexia theories, sentence comprehension theories, and text comprehension theories. In disagreement with the models of word reading that make precise predictions (Coltheart, Rastle, Perry, Langdon, \& Ziegler, 2001), reading comprehension cannot be limited to some specific models. A general framework entailing subsystems of reading comprehension is needed to encompass all the components of reading comprehension (Perfetti \& Stafura, 2014).

\subsection{Reading Impairment Versus Dyslexia}

Hulme and Snowling (2011) indicated that reading intends to extract meaning from text, and this process relies on decoding and comprehension skills. Accurate reading differs from reading comprehension as research has 
significantly shown that many children can read accurately, yet they have poor comprehension. As such, reading-comprehension impairment is common and it is usually not identified in the classroom. Reading comprehension impairment is characterized by several oral-language weaknesses, which hinder the students' comprehension of written and spoken language. Some research indicated that the fundamental oral-language difficulties can be decreased by school-based interventions, which could enhance the reading- and listening-comprehension skills of learners with reading difficulties. The early interventions could lessen and minimize the language-learning weaknesses and could have significant educational and reading comprehension implications.

\subsection{Strategy Intervention Theory}

The meta-analysis research conducted by Galuschka et al. (2014) showed that reading and spelling problems can be diminished with suitable treatment. Learners with dyslexia in all grade levels pass through many emotional traumas that are caused by severe reading and spelling difficulties. As such, interventions are significantly needed to support all learners with dyslexia. Breznitz et al. (2013) indicated that readers with dyslexia in all school and university levels encounter reading impairments and difficulties which hinder their reading comprehension and reading accuracy and make them less accurate readers in comparison with their non-dyslexic peers. The persistence of reading disorders that lasts into adulthood, notwithstanding experience, has been moderately accredited to a decrease in brain malleability beyond childhood. In alignment with such view, research (Breznitz et al., 2013) significantly showed that corrective interventions could be less effective in adults. However, research proved that effective interventions could be effective in enhancing memory processes.

McCray (2001) indicated that millions of youngsters at the intermediate and middle school levels read below a fourth-grade level and experience deficiencies in basic reading skills such as word recognition, decoding, reading fluency, and reading comprehension. He also reported that reading underachievement in the United States in the intermediate and middle school grades, and subsequent academic failure and dropout after eighth grade, indicates the need for immediate, explicit, and effective reading interventions for students at risk and with reading disabilities. Typically, middle school teachers expect students to be independent learners who are capable of completing reading assignments, homework, and projects, and who can demonstrate mastery of subject content on tests. Thus, the middle school represents a critical transition period for readers in which some struggle with the basics while their teachers may expect them to make applications of established reading skills to subject matter reading and learning. According to the International Reading Association, many researchers and educators believe that students must acquire and develop reading skills as early as possible and must be taught effectively; however, little evidence is available on how these abilities are best acquired and taught during secondary school (Leu, 2002).

Reading comprehension interventions have indeed generated remarkable gains in reading for students with learning disabilities. This is, especially when the instructional process utilizes strategy instruction to help the students with the organization of the reading material into meaningful structures and themes of related content (Braten, Amundsen, \& Samuelstein, 2010; Coleman, Gregg, McCain, \& Bellair, 2009;). Similarly, researchers such as Zimmerman (1989) also assert that reading difficulty and dyslexia problems might be compensated especially upon the implementation of "[...] such methods as organizing and transforming information, self con-sequencing, seeking information, and rehearsing or using memory aids" (p. 329). Zimmerman (1989) suggests that the major reading problems of individuals with dyslexia may be alleviated upon the implementation of strategies that are helpful in assisting the students in their self-regulation of their own learning, and defined self-regulated learning strategies as "[...] actions and processes directed at acquiring information or skill that involves agency, purpose, and instrumentality perceptions by learners" (p. 329). This suggests that strategy instruction may particularly be useful and efficacious in enhancing the reading comprehension of the learners with dyslexia.

\subsection{Dyslexia and Gender Gap in Reading Difficulties}

Gender differences in reading difficulty exist and are attributable mainly to male susceptibility as opposite to ascertainment bias. However, ascertainment bias could take place as boys with reading problems are more likely than girls to show disruption resultant from their reading problem (Quinn \& Wagner, 2015). Reading difficulties and behavior problems are more common in boys than in girls (McIntosh, Reinke, Kelm, \& Sadler, 2013). Girls differ from boys in their social functioning (DiPrete \& Jennings, 2012). Gender should be considered when psychosocial functioning is addressed. Girls demonstrate stronger social and behavioral skills than those of young boys, so there will be academic gender gap as girls could outperform boys in reading achievement (McIntosh, Reinke, Kelm, \& Sadler, 2013; DiPrete \& Jennings, 2012). 


\section{Method}

The present study was conducted in two tremendously big private and two public schools located in Beirut city, the capital of Lebanon, a country where English is taught as a school subject, starting with pre-school and up to grade 12. Previous research is either scanty or non-existent with regard to the effectiveness of appropriate implementation of combined strategy instruction in the study context where inclusion is applied. This study addresses the following research questions:

1) It has been proved that combined strategy instruction enhances learning when applied to groups of students with dyslexia. Is therefore combined strategy instruction more effective than regular instruction in improving the reading comprehension within the frame of the inclusion theory?

2) Are there gender-related differences in the reading comprehension scores of male and female participants in an inclusive classroom?

3) Will the study participants who come from private schools surpass their counterparts from public schools in comprehending the texts in inclusive classrooms?

\subsection{Participants}

Upon surveying the students with dyslexia whose parents submitted upon enrollment reports to the school indicating that their children have dyslexia, the researchers sampled the study participants. A total sample of 298 students of English as a foreign language were sampled from public and private schools, located in Beirut, the capital of Lebanon; 281 students are without dyslexia and 17 students are with dyslexia: 84 subjects of $7^{\text {th }}$ grade (78 students without dyslexia and 6 students with dyslexia), 74 subjects of $8^{\text {th }}$ grade (70 students without dyslexia and 4 students with dyslexia), 67 subjects of $9^{\text {th }}$ grade (64 students without dyslexia and 3 students with dyslexia), and 73 subjects of $10^{\text {th }}$ grade (69 students without dyslexia and 4 students with dyslexia). In order to set the study within the frame of the inclusion theory, all the participants were mixed in the groups. They were all randomly assigned to control and experimental conditions, and the sample included a total of 193 males and 105 females. The experimental groups received instructions according to the procedures of combined strategy instruction, while the control group received regular instruction. All the participants were native speakers of Arabic and came from different socio-economic backgrounds. They were studying EFL at a rate of 6 hours per week in accordance with the curriculum requirements proclaimed by the National Ministry of Education. There was an experimental and a control group in each type of school (private and public). The reason of taking students from both types of schools is due to the different socio-economic background of the students, to the fact that private schools employ more trained teachers and are better equipped with technology. Therefore, a priori it seems that the study participants who come from private schools will surpass their counterparts from public schools.

\subsection{Instruments}

The instruments used to collect data and measure the variables of reading comprehension proficiency under investigation included pre-tests and post-tests of reading comprehension proficiency including test items, which reflect the strategies of the combined treatment used in the study. The pre-tests and post-tests included narrative passages, graphic organizers, visual displays, mnemonic illustrations, computer-assisted instruction, main idea identification, summarization, questioning, surveying (skimming and scanning) and pre-reading activities.

\subsection{Procedure}

The treatment lasted for four months at the rate of 6 contact hours per week. The treatment given to participants in the private schools included the full combined strategy instruction consisting of graphic organizers, visual displays, mnemonic illustrations, computer exercises, predicting, inference, text structure awareness, main idea identification, summarization, and questioning. The treatment given in the public schools was the same combined strategy instruction but lacking the computer exercises due to the unavailability of equipment needed.

In order to start the experiment, the first step was for the researchers to discuss the basics of the study with the principals of the four schools, receive the referral reports of the students with dyslexia and ask students with dyslexia to fill in the dyslexia survey and dyslexia verification forms. With the support of the counselors of the Ministry of Education and Higher Education, the teachers (who held a Bachelor degree in Education and had years of experience ranging from 5 to 15) received a 5-day training on the use of each strategy of the combined strategy instruction. It was agreed with the principals of the schools that there would be a full inclusion of students with dyslexia along with those without dyslexia in the same classrooms.

The materials utilized in the study were discussed and disseminated at the very beginning of the academic year 
so that the teachers could know what to teach, how to sequence the instruction, and how to employ the appropriate methods and strategies to be implemented in this research. The teachers became experts on language and reading due to the resources they received. The students answered a pre-test and a post-test at the beginning and at the end of the treatment.

\subsection{Reliability of Scoring}

The reliability of the scoring was tested by getting half the tests judged by another scorer after the researchers had finished scoring them. Tests were picked up at random and were given to the other scorer along with the given and evolved criteria. Likewise, a third teacher was consulted in case of doubt, and consensus was reached through discussion to ensure agreements of ratings. The Statistical Package for Social Sciences (SPSS) was used to perform item analysis to ensure reliability of the study instruments through an acceptable alpha reliability coefficient of internal consistency. Likewise, inter-rater reliability among reported scores of independent judges was computed to ensure high inter-rater reliability correlations

\subsection{Validity of the Instruments}

The tests employed in the study enabled the teachers to judge students' abilities to read, understand, analyze, and interpret material as well as to express themselves in their own words. Besides, such tests could pose several questions, so their content validity proved to be high. Additionally, the items of the tests measured the curriculum objectives accurately because these tests were tailored in accordance with the covered and given instruction. The tests, examined in this research, used uniform procedures for administration and scoring in order to assure that the results from different students could be comparable. Consequently, a specification table that matched the objectives to the test items as well as expert judgment was used to ensure the content validity of the pre-tests and post-tests used in the study. As such, to ensure internal validity and reliability, the teachers received training on the use of the 10 reading strategies forming the combined strategy instruction; furthermore, the same supplementary and basic materials and tests were employed.

\section{Results}

The Statistical Package for Social Sciences (SPSS, version 21) was used for data analysis of collected data. Appropriate pre-tests and post-tests specifically designed and validated for the purpose of the study were developed and administered. Descriptive statistics (mean scores, and standard deviations) as well as inferential statistics (three-way Analysis of Covariance) tests were used to address the questions and test the hypotheses formulated for the study. The treatment conditions (experimental versus control) were used as independent variables, the pre-test scores as covariates, and the post-test scores as dependent variables. The gender and school type variables were also used as moderator variables in order to test for possible interaction effects on comprehension among these variables and the treatment conditions.

\subsection{Analysis of the Data}

The study participants were a total of eight cohorts of male and female middle school Lebanese learners coming from public and private schools who were studying English as a first foreign language. In each group, there were both learners with and learners without dyslexia.

\subsection{Graders 7 Results:}

A total of 84 grade 7 students participated in the study: there were 39 students in the experimental group (45.9\%) enrolled in 2 classes and $45(52.09 \%)$ in the control group enrolled 2 classes as well; 55 male participants (64.7\%), 29 female participants; 45 participants $(52.9 \%)$ from public schools, $39(45.9 \%)$ from private schools.

Table 1. Descriptive Statistics and F Values for Effects of Treatment, Gender, School Type and interactions Comprehension of Narrative Texts of Grade 7

\begin{tabular}{|c|c|c|c|c|c|c|c|c|}
\hline Variable & $\mathrm{M}$ & SD & $\mathrm{M}$ & SD & $\mathrm{F}$ & $\mathrm{df}$ & $\mathrm{P}$ & y2 \\
\hline \multirow[t]{2}{*}{ Treatment } & \multicolumn{2}{|c|}{ Control $n=42$} & \multicolumn{6}{|c|}{ Experimental $\mathrm{n}=33$} \\
\hline & 21.09 & 7.92 & 31.73 & 6.25 & 27.62 & 1.75 & $.00 *$ & .29 \\
\hline \multirow[t]{2}{*}{ Gender } & \multicolumn{2}{|c|}{$\underline{\text { Male } n}=49$} & \multicolumn{6}{|c|}{ Female $n=26$} \\
\hline & 23.48 & 8.13 & 29.63 & 8.86 & .57 & 1.75 & .45 & .00 \\
\hline School Type & \multicolumn{2}{|c|}{ Public $\mathrm{n}=40$} & \multicolumn{6}{|c|}{ Private $n=35$} \\
\hline
\end{tabular}




$\begin{array}{llllllll}21.10 & 6.88 & 30.78 & 8.01 & 14.75 & 1.75 & .00 * & .18 \\ & & & .26 & 1.75 & .60 & .00 \\ & & & .02 & 1.75 & .86 & .00 \\ & & & 3.59 & 1.75 & .74 & .00 \\ & & & & 2.22 & 1.75 & .14 & .03\end{array}$

Treatment x Gender

Treatment $x$ School Type

Gender $\mathrm{x}$ School Type

$\mathrm{P}<.05$.

The results in Table 1 show that the experimental group participants who received combined strategy instruction outperformed their control group counterparts in reading comprehension achievement $\mathrm{F}(1,75)=27.62, \mathrm{P}=.00$, $\mathrm{\eta} 2=.29$. Similarly, there was a statistically significant difference in favor of the private school participants who did better than the public-school learners in comprehending narrative texts. $\mathrm{F}(1,75)=14.75, \mathrm{P}=.00, \mathrm{y} 2=.18$. Conversely, there was no statistically significant effect for the gender variable on the reading comprehension $\mathrm{F}$ $(1,75)=.57, \mathrm{P}=.45, \mathrm{y} 2=.00$. The analysis of the grade 7 results shows no statistically significant interaction differences by treatment and gender $\mathrm{F}(1,75)=.26, \mathrm{P}=.60, \mathrm{y} 2.00$; treatment by school type $\mathrm{F}(1,75)=.02$, $\mathrm{P}=.86, \mathrm{y} .00$; gender and school type $\mathrm{F}(1,75)=3.59, \mathrm{P}=.7 \mathrm{~g} .00$; and treatment, gender, and school type $\mathrm{F}(1,75)$ $=2.22, \mathrm{P}=.14, \mathrm{y} 2=.03$.

\subsection{Graders 8 Results:}

A total of 74 grade 8 students participated in the study: 38 students in the experimental group (51.4\%) and 36 (48.6\%) in the control group; 52 male participants (70.3\%), 22 female participants (29.7\%); 42 participants (56.8) from public schools, and $32(20.1 \%)$ from private schools.

Table 2. Descriptive Statistics and F Values for Effects of Treatment, Gender, School Type and interactions Comprehension of Narrative Texts of Grade 8

\begin{tabular}{|c|c|c|c|c|c|c|c|c|}
\hline Variable & $\mathrm{M}$ & SD & $\mathrm{M}$ & SD & F & $\mathrm{df}$ & $\mathrm{P}$ & $\mathrm{y}$ \\
\hline \multirow[t]{2}{*}{ Treatment } & \multicolumn{2}{|c|}{ Control $n=35$} & \multicolumn{6}{|c|}{ Experimental $\mathrm{n}=35$} \\
\hline & 19.80 & 7.73 & 33.65 & 7.80 & 10.98 & 1.70 & $.00^{*}$ & 15 \\
\hline \multirow[t]{2}{*}{ Gender } & \multicolumn{2}{|c|}{ Male $\mathrm{n}=48$} & \multicolumn{6}{|c|}{ Female $\mathrm{n}=22$} \\
\hline & 25.92 & 9.55 & 29.36 & 11.84 & .11 & 1.70 & .74 & .00 \\
\hline \multirow[t]{2}{*}{ School Type } & \multicolumn{2}{|c|}{$\underline{\text { Public } \mathrm{n}=38}$} & \multicolumn{6}{|c|}{ Private $\mathrm{n}=32$} \\
\hline & 25.11 & 8.90 & 28.64 & 11.80 & 6.06 & 1.70 & $.01 *$ & .09 \\
\hline Treatment x Gender & & & & & 2.06 & 1.70 & .15 & .03 \\
\hline Treatment x School Type & & & & & .07 & 1.70 & .78 & .00 \\
\hline Gender x School Type & & & & & 1.61 & 1.70 & .20 & .02 \\
\hline Treatment $x$ Gender x School type & & & & & 04 & 1.70 & .82 & .00 \\
\hline
\end{tabular}

$* \mathrm{P}<.05$.

Analysis of the grade 8 results shows that the experimental group participants who received combined strategy instruction outperformed their control group counterparts in reading comprehension achievement $\mathrm{F}(1,70)=$ $10.98, \mathrm{P}=.00, \mathrm{y} 2=.15$. Similarly, there was a statistically significant difference in favor of the private school participants who did better than the public-school learners in comprehending narrative texts. $F(1,70)=6.06, \mathrm{P}$ $=.01, \mathrm{y} 2=.09$.

Conversely, there was no statistically significant effect for the gender variable on the reading comprehension $\mathrm{F}$ $(1,70)=.01, \mathrm{P}=.74, \mathrm{y} 2=.00$. The analysis of the grade 8 results shows no statistically significant interaction differences by treatment and gender $\mathrm{F}(1,70)=2.06, \mathrm{P}=.15, \mathrm{y} .03$; treatment and school type $\mathrm{F}(1,70)=.07$, $\mathrm{P}=.78, \mathrm{y} .00$; gender and school Type $\mathrm{F}(1,70)=1.61, \mathrm{P}=.20 \mathrm{y} .00$; or by treatment, gender, and school type $\mathrm{F}$ $(1,70) .04, \mathrm{P}=.82, \mathrm{y} .03$. 


\subsection{Graders 9 Results:}

A total of 67 grade 9 students participated in the study: 35 students in the experimental group (52.2\%) and 32 (47.8) in the control group; 43 male participants (64.2\%), and 24 female participants (35.8\%); 27 participants (40.3\%) from public schools and 40 (59.7\%) from private schools.

Table 3. Descriptive Statistics and F Values for Effects of Treatment, Gender, School Type and interactions Comprehension of Narrative Texts of Grade 9

\begin{tabular}{|c|c|c|c|c|c|c|c|c|}
\hline Variable & $\mathrm{M}$ & SD & M & SD & $\mathrm{F}$ & $\mathrm{df}$ & $\mathrm{P}$ & $\mathrm{y}$ \\
\hline \multirow[t]{2}{*}{ Treatment } & \multicolumn{2}{|c|}{ Control $\mathrm{n}=25$} & \multicolumn{6}{|c|}{ Experimental $\mathrm{n}=35$} \\
\hline & 23.28 & 6.02 & 25.54 & 6.56 & .19 & 1.60 & .65 & .00 \\
\hline \multirow[t]{2}{*}{ Gender } & \multicolumn{2}{|c|}{$\underline{\text { Male } n=40}$} & \multicolumn{6}{|c|}{$\underline{\text { Female } \mathrm{n}=20}$} \\
\hline & 24.87 & 6.84 & 22.55 & 6.15 & .31 & 1.60 & .57 & .00 \\
\hline \multirow[t]{2}{*}{ School Type } & \multicolumn{2}{|c|}{$\underline{\text { Public } n=27}$} & \multicolumn{2}{|c|}{$\underline{\text { Private } n=33}$} & & & & \\
\hline & 28.74 & 4.22 & 21.21 & 5.87 & 28.36 & 1.60 & $.00^{*}$ & .35 \\
\hline Treatment $\mathrm{x}$ Gender & & & & & .06 & 1.60 & .79 & .00 \\
\hline Treatment x School Type & & & & & .48 & 1.60 & .49 & .00 \\
\hline Gender x School Type & & & & & .30 & 1.60 & .58 & .00 \\
\hline Treatment $x$ Gender x School type & & & & & 5.93 & 1.60 & $.01 *$ & .10 \\
\hline
\end{tabular}

$* \mathrm{P}<.05$.

The results show that the public-school participants who received combined strategy instruction outperformed their private school counterparts in reading comprehension achievement $\mathrm{F}(1,60)=28.36, \mathrm{P}=.00, \mathrm{y} 2=.35$. Likewise, the results show a statistically significant difference between treatment, gender, and school type $\mathrm{F}$ $(1,60)=5.93, \mathrm{P}=.01, \mathrm{y} 2.01$. There was no statistically significant difference in the performance of the participants in the control and the experimental group. $\mathrm{F}(1,60)=.19, \mathrm{P}=.65, \mathrm{y} 2=.00$. Similarly, there was no statistically significant effect for the gender variable on the reading comprehension of the grade 9 participants $\mathrm{F}$ $(1,60)=.31, \mathrm{P}=.57, \mathrm{y} 2=.00$. Likewise, the analysis of the grade 9 results shows no statistically significant interaction differences by treatment and gender $\mathrm{F}(1,60)=.06, \mathrm{P}=.79, \mathrm{y} 2.00$, treatment by school type $\mathrm{F}(1,60)$ $=.48, \mathrm{P}=.49, \mathrm{y} .00$; gender and school type $\mathrm{F}(1,60)=.30, \mathrm{P}=.58 \mathrm{y} .00$.

The preceding findings hint the importance of the class-specific contextual variables as possible determinants of the grade 9 dyslexic readers of expository text. Unlike in grades 7 and 8, the public school rather than the private school readers did better in reading expository texts. The findings of the analysis of the grade 9 results also indicate a statistically significant interaction between the treatment conditions, school type and gender, which call for the need for further research that focuses on specific cases of individual learners of small groups of learners who are dyslexic in order to determine the individual and context-specific factors that may impact their reading achievement.

\subsection{Graders 10 Results:}

A total of 73 grade 10 students participated in the study: 37 students in the experimental group (50.7\%) and 36 $(49.3 \%)$ in the experimental group; 43 male participants $(58.1 \%)$ and 31 female participants $(41.9 \%)$; 44 participants $(60.3 \%)$ from public schools and $29(39.7 \%)$ from private schools.

Table 4. Descriptive Statistics and F Values for Effects of Treatment, Gender, School Type and interactions Comprehension of Narrative Texts of Grade 10

\begin{tabular}{|c|c|c|c|c|c|c|c|c|}
\hline Variable & $\mathrm{M}$ & SD & $\mathrm{M}$ & SD & $\mathrm{F}$ & $\mathrm{df}$ & $\mathrm{P}$ & $\mathrm{y}$ \\
\hline \multirow[t]{2}{*}{ Treatment } & \multicolumn{2}{|c|}{ Control $n=35$} & \multicolumn{2}{|c|}{ Experimental $\mathrm{n}=31$} & & & & \\
\hline & 24.41 & 8.70 & 30.59 & 6.46 & .29 & 1.66 & .58 & .00 \\
\hline Gender & \multicolumn{2}{|c|}{ Male $n=39$} & \multicolumn{2}{|c|}{ Female $\mathrm{n}=27$} & & & & \\
\hline
\end{tabular}




\begin{tabular}{|c|c|c|c|c|c|c|c|c|}
\hline \multirow{3}{*}{ School Type } & 27.83 & 8.72 & 26.57 & 7.68 & .25 & 1.66 & .61 & .00 \\
\hline & \multicolumn{2}{|c|}{$\underline{\text { Public } n=43}$} & \multicolumn{6}{|c|}{$\underline{\text { Private } \mathrm{n}=23}$} \\
\hline & 26.65 & 8.61 & 28.56 & 7.64 & .11 & 1.66 & .73 & .00 \\
\hline Treatment $\mathrm{x}$ Gender & & & & & .01 & 1.66 & .91 & .00 \\
\hline Treatment x School Type & & & & & .00 & 1.66 & .96 & .00 \\
\hline Gender x School Type & & & & & .17 & 1.66 & .67 & .00 \\
\hline Treatment x Gender x School type & & & & & .51 & 1.66 & .47 & \\
\hline
\end{tabular}

$* \mathrm{P}<.05$.

The results show that there was no statistically significant difference in the performance of experimental group participants who received combined strategy instruction and the performance of their control group counterparts in reading comprehension achievement $\mathrm{F}(1,66)=.29, \mathrm{P}=.58, \mathrm{y} 2=.00$. Similarly, there was no statistically significant difference by gender in comprehending expository texts. $\mathrm{F}(1,66)=.25, \mathrm{P}=.61, \mathrm{y} 2=.00$. Furthermore, there was no statistically significant effect for the school type variable on the reading comprehension of the participants. $\mathrm{F}(1,66)=.11, \mathrm{P}=.73, \mathrm{y} 2=.00$. Likewise, the analysis of the grade 10 results shows no statistically significant interaction differences by treatment and gender $\mathrm{F}(1,66)=.01, \mathrm{P}=.091$, $\mathrm{\eta} 2.00$; treatment by school type $\mathrm{F}(1,66)=.00, \mathrm{P}=.96, \mathrm{y} .00$; gender and school type $\mathrm{F}(1,66)=17, \mathrm{P}=.67 \mathrm{y} .00$; and treatment, gender, and school type $\mathrm{F}(1,66)=.51, \mathrm{P}=.47, \mathrm{y} 2.00$.

These findings suggest that neither the treatment conditions (control versus experimental) nor the school type (private versus public) have had an impact on the reading achievement of the grade 10 dyslexic learners. This underscores the importance of other school, teacher, or classroom related factors as possible important determinants of reading the grade 10 reading comprehension.

\section{Discussion}

This study was reported the effect of the inclusion theory when the combined strategy instruction on improving the reading comprehension is applied. It is well-known that the implementation of strategies to help students in their process of acquiring a good reading comprehension skill in a foreign language has positive results for both students with and without dyslexia. But there is no research conducted to establish a solid ground to know if the inclusion of students with dyslexia in a regular class may change these positive results that exist in both groups.

The results of students who worked with narrative texts (grades 7 and 8) showed that the experimental group participants who received combined strategy instruction to understand narrative texts outperformed their control group counterparts in reading comprehension achievement.

Similarly, there was a statistically significant difference in favor of the private school participants who did better than the public-school learners in comprehending narrative texts. These findings suggest that the learning environment of the private schools which participated in the study might be more organized and effective than those of the public schools. It is worth noting that the private schools used computers to implement some of the strategies. This factor should be considered to be even further studied.

Equally important is the fact that students who enroll in public school in the context of the present study usually come from less advantaged socio-economic backgrounds, which can have negatively impacted their academic achievement in general, and reading achievement. Conversely, there was no statistically significant effect for the gender variable on the reading comprehension of the participants.

The results of grade 9 participants (using expository texts) revealed a statistically significant difference by school type in favor of the public school participants who did better than their private school counterparts in comprehending expository texts. These findings contradict those of grade 7,8 and 10. This underscores the importance of contextual variables as determinants of academic achievement in general and reading comprehension. These variables and determinants mav be student and teacher-related and/or school environment of administrative-leadership determined.

The results also indicate that, in grade 9 , there is a statistically significant difference for the interaction between treatment, gender, and school type. Conversely, there was no statistically significant difference in the performance of the participants in the control and the experimental group and no statistically significant effect for the gender variable. 
The findings of grade 10 (using expository texts) of the present study showed that there was no statistically significant difference between the experimental group and the control group. Similarly, there was no statistically significant difference by gender in comprehending expository texts. Likewise, analysis of the grade 10 results shows no statistically significant interaction differences by treatment and gender. Similarly, there was a statistically significant interaction between treatment conditions, gender, and school type of the participants. Conversely, there was no statistically significant effect for the treatment conditions on reading comprehension, nor by gender and no statistically significant interaction differences by treatment and gender.

The study findings don't also endorse those of McIntosh, Reinke, Kelm, and Sadler (2013) and DiPrete and Jennings (2012) who indicated that reading difficulties are more common in boys than in girls, and Girls differ from boys in their social functioning since, due to academic gender gap, they could demonstrate stronger social and behavioral skills than those of young boys.

\section{Conclusions and Implications}

The first research question is if the combined strategy instruction is more effective than regular instruction in improving the reading comprehension within the frame of the inclusion theory as it has been proved in groups of only learners with dyslexia or only learners without dyslexia. The present study concludes that combined strategy instruction in the field of the inclusion theory is more effective than regular instruction in improving reading comprehension of both students with and without dyslexia when using narrative texts (grades 7 and 8) in the classroom, but there's no difference, when using expository texts (grades 9 and 10). This could be due to the fact that students with dyslexia often experience severe problems in comprehending expository texts despite fluent decoding skills (Williams, 2001). According to Griffin and Tulbert (1995), expository texts are difficult for students with dyslexia due to the difficulties posed by the structures, vocabulary complex concepts, unfamiliar typographical features peculiar organizational structures, and numerous tables and figures" (p. 73). The present study showed that students with dyslexia like students without dyslexia may need special attention in the classroom to understand this type of texts. In this case, it seems that the combined strategy instruction is not effective, or at least, not effective as the unique methodology is applied.

The second research question presents gender as an important element of the study. There was no significant difference by gender in all the grade levels under study. Neither was any statistically significant interaction between the gender of the participants and their school type across the entire grade levels; no differences in the interaction between gender and treatment conditions (control versus experimental) were shown. Furthermore, no gender gaps were statistically shown when combining the treatment conditions, the school type and gender across all the grade levels under study except in grade 9.

Regarding the third question, we can state that there are no statistical differences among grades in the interaction between treatment and school type, which indicates that in general, the treatment conditions were equally effective both in the private as well as public schools. The fact that only in one group (grade 9) the private school students got better results cannot be related to the treatment applied, but suggests that certain classroom contextual variables may have impacted the efficacy of the treatment of combined strategy instruction in improving reading comprehension. Due to the different results in grade 9, further research is needed to address the last two research questions. As such, the findings of the study partially align with those of Ellis, McDougall, and Monk (1996) and Treiman and Hirsh-Pasek (1985) who indicated that young students with dyslexia could have similar reading performance of those without dyslexia, and even learners with dyslexia could be faster at some visual processing tasks. Furthermore, a major limitation of the study is that the intervention in public schools lacked the computer exercises due to the unavailability of the needed equipment. As such, further research should be conducted upon equipping the public schools with all the equipment available at private schools.

\section{References}

Breznitz, Z., Shaul, S., Horowitz-Kraus, T., Sela, I., Nevat, M., \& Karni, A. (2013). Enhanced reading by training with imposed time constraint in typical and dyslexic adults. Nature communications, 4, 1486. https://doi.org/10.1038/ncomms 2488

Braten, I., Amundsen, A., \& Samuelstuen, M. S. (2010). Poor readers-good learners: A study of dyslexic readers learning with and without text. Reading \& Writing Quarterly, 26(2), 166-187. https://doi.org/10.1080/10573560903123684

Bunch, G., Finnegan, K., Humphries, C., Doré, R., \& Doré, L. (2005). Finding a way through the maze: Crucial terms used in education provision for Canadians with Disabilities. Toronto, ON, Canada: The Marsha 
Forest Centre.

Coleman, C., Gregg, N., McCain, L., \& Bellair, L.W. (2009). A comparison of spelling performance across young adults with and without dyslexia. Assessment for Effective Intervention, 34, 94-105. https://doi.org/10.1177/1534508408318808

Coltheart, M., Rastle, K., Perry, C., Langdon, R., \& Ziegler, J. (2001). DRC: a dual route cascaded model of visual word recognition and reading aloud. Psychological review, 108(1), 204. https://doi.org/10.1037/0033-295X.108.1.204

Deacon S. H., Parrila, R., \& Kirby, J. R. (2006). Processing of derived forms in high-functioning dyslexics. Annals of Dyslexia, 56(1), 103-127. https://doi.org/10.1007/s11881-006-0005-3

DiPrete, T. A., \& Jennings, J. L. (2012). Social and behavioral skills and the gender gap in early educational achievement. Social Science Research, 41(1), 1-15. https://doi.org/10.1016/j.ssresearch.2011.09.001

Edmonds, M. S., Vaughn, S., Wexler, J., Reutebuch, C., Cable, A., Tackett, K. K., \& Schnakenberg, J. W. (2009). A synthesis of reading interventions and effects on reading comprehension outcomes for older struggling readers. Review of Educational Research, 79(1), 262-300. https://doi.org/10.3102/0034654308325998

Ellis, A. W., McDougall, S. J., \& Monk, A. F. (1996). Are dyslexics different? I. A comparison between dyslexics, reading age controls, poor readers and precocious readers. Dyslexia, 2(1), 31-58. https://doi.org/10.1002/(SICI)1099-0909(199602)2:1\%3C59::AID-DYS35\%3E3.0.CO;2-K

Florian, L., Young, K., \& Rouse, M. (2010). Preparing teachers for inclusive and diverse educational environments: Studying curricular reform in an initial teacher education course. International Journal of Inclusive Education, 14(7), 709-722. https://doi.org/10.1080/13603111003778536

Galuschka, K., Ise, E., Krick, K., \& Schulte-Körne, G. (2014). Effectiveness of treatment approaches for children and adolescents with reading disabilities: a meta-analysis of randomized controlled trials. PloS one, 9(2), e89900. https://doi.org/10.1371/journal.pone.0089900

Goodwin, A. P., \& Ahn, S. (2013). A Meta-Analysis of Morphological Interventions in English: Effects on Literacy Outcomes for School-Age Children. Scientific Studies of Reading, 17(4), 257-285. https://doi.org/10.1080/10888438.2012.689791

Griffin, C. C., \& Tulbert, B. L. (1995). The effect of graphic organizers on students' comprehension and recall of expository text: A review of the research and implications for practice. Reading and Writing Quarterly, 11(1), 73-89. https://doi.org/10.1080/1057356950110106

Heikkila, E., \& Knight, A. (2012). Inclusive music teaching strategies for elementary-age children with $\begin{array}{lllll}\text { developmental } \quad \text { Myslexia. } & \text { Music }\end{array}$ https://doi.org/10.1177/0027432112452597

Honig, B., Diamond, L., Gutlohn, L., Fertig, B., Daniel, H., Zemelman, S., \& Steineke, N. (2008). Teaching reading sourcebook (Vol. 3, No. 2, p. 1). Arena Press; 2nd edition (April 15, 2008).

Hulme, C., \& Snowling, M. J. (2011). Children's reading comprehension difficulties: Nature, causes, and treatments. Current Directions in Psychological Science, 20(3), 139-142. https://doi.org/10.1177/0963721411408673

Kintsch, W. (1988). The role of knowledge in discourse comprehension: A construction-integration model. Psychological review, 95(2), 163. https://doi.org/10.1037/0033-295X.95.2.163

Kemp, G., Segal, J., \& Cutter, D. (2009). Learning disabilities in children: Learning disability symptoms, types and testing. http://helpguide.org/mental/learning_disabilities.htm\#

Leu, D. J. (2002). The new literacies: Research on reading instruction with the Internet and other digital technologies. What research has to say about reading instruction, 3, 310-336.

Logemann, J. A. (2000). What is evidence-based practice and why should we care? ASHA Leader, 3.

McCray, A. D. (2001). Middle school students with reading disabilities. The Reading Teacher, 55(3), 298-300. 183.

Macdonald, S. J. (2009). Towards a Sociology of Dyslexia: Exploring links between Dyslexia, Disability, and Social Class: Saarbrücken, VDM Publishing House Ltd.

Mastropieri, M. A., Scruggs, T. E., \& Chung, S. (1997). Qualitative and quantitative outcomes associated with inclusive science teaching. Paper presented at the annual meeting of the American Educational Research 
Association, Chicago. Retrieved from http://www.auckland.ac.nz/uoa/

McIntosh, K., Reinke, W. M., Kelm, J. L., \& Sadler, C. A. (2013). Gender differences in reading skill and problem behavior in elementary school. Journal of Positive Behavior Interventions, 15(1), 51-60. https://doi.org/10.1177/1098300712459080

Ness, M. (2011). Explicit reading comprehension instruction in elementary classrooms: Teacher use of reading comprehension strategies. Journal of Research in Childhood Education, 25(1), 98-117. https://doi.org/10.1080/02568543.2010.531076

Perfetti, C., \& Stafura, J. (2014). Word knowledge in a theory of reading comprehension. Scientific Studies of Reading, 18(1), 22-37. https://doi.org/10.1080/10888438.2013.827687

Pressley, M. (2008). What the future of reading research could be. Comprehension instruction: Research-based best practices, 2, 391-413.

Reid, D. K., \& Valle, J. W. (2004). The discursive practice of learning disability: Implications for instruction and parent-school relations. Special Series: Journal of Learning Disabilities, 37(6), 466-481. https://doi.org/10.1177/00222194040370060101

Riddick, B. (2001). Dyslexia and inclusion: time for a social model of disability perspective? International studies in sociology of education, 11(3), 223-236. https://doi.org/10.1080/09620210100200078

Sapon - Shevin, M. (1996). Full inclusion as disclosing tablet: Revealing the flaws in our present system. Theory into practice, 35(1), 35-41. https://doi.org/10.1080/00405849609543699

Shevlin, M., Winter, E., \& Flynn, P. (2013). Developing inclusive practice: teacher perceptions of opportunities and constraints in the Republic of Ireland. International Journal of Inclusive Education, 17(10), 1119-1133. https://doi.org/10.1080/13603116.2012.742143

Suggate, S. P. (2016). A meta-analysis of the long-term effects of phonemic awareness, phonics, fluency, and reading comprehension interventions. Journal of learning disabilities, 49(1), 77-96. https://doi.org/10.1177/0022219414528540

Swanson, H. L. (1999). Reading research for students with LD: A meta-analysis of intervention outcomes. Journal of Learning Disabilities, 32(6), 504-532. https://doi.org/10.1177/002221949903200605

Treiman, R., \& Hirsh-Pasek, K. (1985). Are there qualitative differences in reading behavior between dyslexics and normal readers?. Memory \& Cognition, 13(4), 357-364. https://doi.org/10.3758/BF03202503

Quinn, J. M., \& Wagner, R. K. (2015). Gender differences in reading impairment and in the identification of impaired readers: Results from a large-scale study of at-risk readers. Journal of learning disabilities, 48(4), 433-445. https://doi.org/10.1177/0022219413508323

Van Dijk, T. A., Kintsch, W., \& Van Dijk, T. A. (1983). Strategies of discourse comprehension (pp. 11-12). New York: Academic Press.

Williams, A. (2001). Using Integrated Learning Systems to support the students with learning difficulties in a comprehensive school. Support for Learning, 16, 174-178. https://doi.org/10.1111/1467-9604.00214

Zimmerman, B. J. (1989). A social cognitive view of self-regulated academic learning. Journal of Educational Psychology, 81, 329-339. https://doi.org/10.1037/0022-0663.81.3.329

\section{Copyrights}

Copyright for this article is retained by the author(s), with first publication rights granted to the journal.

This is an open-access article distributed under the terms and conditions of the Creative Commons Attribution license (http://creativecommons.org/licenses/by/4.0/). 